\title{
The evaluation of morphology of renal pelvicalyceal system's and infundibulopelvic anatomy of kidney's lower pole in post-mortem series
}

\author{
R. Çiçek¹, G. Dündar²®, K. Gökçen³ ${ }^{3}$ G. Gökçe, E.Y. Gültekin ${ }^{4}$ \\ 'Department of Urology, Malatya Training and Research Hospital, Malatya, Turkey \\ 2Department of Urology, University of Health Sciences, Bursa Yuksek Ihtisas Training and Research Hospital, Bursa, Turkey \\ ${ }^{3}$ Department of Urology, Bahçeşehir University, Medical Park Göztepe Hospital, Istanbul, Turkey \\ ${ }^{4}$ Department of Urology, Cumhuriyet University, Faculty of Medicine, Sivas, Turkey
}

[Received: 11 March 2021; Accepted: 28 March 2021; Early publication date: 13 April 2021]

Background: Urinary system stones are frequently encountered in the community. Together with technological developments, introduction of new treatment procedures such as extracorporeal shock wave lithotripsy, percutaneous nephrolithotomy and retrograde intrarenal surgery has further reduced morbidity, mortality and hospitalisation time of patients. In order to maximise success and to reduce complications of these procedures, it is necessary to evaluate anatomy and morphological differences of kidney collector system before the procedure. This study was conducted for the purpose of determining the morphology of the kidney collector system and the negative anatomic factors of the lower pole in autopsy cases performed in our institution.

Materials and methods: Eighty two kidney units obtained from 41 autopsy cases conducted in Faculty of Medicine Department of Forensic Medicine, Sivas Cumhuriyet University between September 2017 and September 2018 were included in the study. Percentages were found as $78 \%$ for intrarenal pelvis, $13.4 \%$ for borderline pelvis, $6.1 \%$ for extrarenal pelvis and $2.4 \%$ for pelvic nonexistence. When pelvicalyceal anatomy was evaluated, percentages were found as $32.9 \%$ for bicalyceal, $26.8 \%$ for tricalyceal, $20.7 \%$ for multicalyceal, and $19.5 \%$ for unclassified calyceality. When it was evaluated according to opening of calyces into the renal pelvis based on Sampaio classification, percentages were found as $30.5 \%$ for Al, $17.1 \%$ for type II, $28 \%$ for $B 1,18.3 \%$ for $B I I$, and $6.1 \%$ for unevaluated part. Infundibular lengths of kidney's lower pole were detected as under $3 \mathrm{~cm}$ in $39 \%$ and over $3 \mathrm{~cm}$ in $61 \%$ of all cases. Infundibulopelvic angles of kidney's lower pole were measured as under $70^{\circ}$ in $42.7 \%$ and over $70^{\circ}$ in $57.3 \%$ of all cases.

Results: In our study, there was no statistically significant difference between the right and left kidneys in terms of collecting system morphology and lower pole's negative anatomical factors. Only infundibular length which is one of the collecting system morphology and lower pole's negative anatomical factors were statistically shorter in females than males. There was no difference in terms of other parameters.

Address for correspondence: Dr. G. Dündar, Department of Urology, University of Health Sciences, Bursa Yuksek Ihtisas Training and Research Hospital, Bursa, Turkey, tel: +90 5052464648, e-mail: dr@gokcedundar.com 
Conclusions: In conclusion, the findings of this study are largely consistent with the results of similar studies. This reveals that renal collecting system morphology and negative anatomic factors in the lower pole collecting system in human are roughly similar. In clinical practice, pre-treatment computed tomography and, if necessary, magnetic resonance urography evaluation of the lower pole negative anatomic factors may contribute to gain preliminary information about both the clearance of stone fragments especially after shock wave lithotripsy and retrograde intrarenal surgery procedures and perioperative complications proactively. (Folia Morphol 2022; 81, 2: 350-358)

Key words: infundibulopelvic angle, infundibulopelvic anatomy, kidney anatomy, post-mortem morphology, kidney morphology, urology

\section{INTRODUCTION}

It is known that the intrarenal calyceal system may vary from person to person [19]. So much so that the possibility of both kidneys being symmetrical in the same person is only $37 \%$ [26].

Various studies have been carried out from past to present to define the kidney morphology. In a study by Ningthoujam et al. [19], where the renal collecting system was evaluated according to the shape and number of calyces, calyceal structures were discussed in four categories: bicalyceal, tricalyceal, multicalyceal and unclassifiable.

Sampaio and Mandarim-De-Lacerda [26] classified the renal collecting system in four different forms according to the openings of the major calyces. According to this type of classification:

- Al: The collecting system is comprised of the combination of the upper and lower calyx groups, and the middle calyx group opens to either the upper or lower, or both collecting systems;

- All: Similar to type A1, but one or both upper and lower calyx groups open to the middle calyx;

- BI: The middle pole of the kidney opens to the renal pelvis independently;

- BII: The minor calyces of the middle pole of the kidney open to the renal pelvis independently.

In another study, Bruce et al. [4] classified the renal pelvis and divided it into four groups as intrarenal, borderline, extrarenal, and absence of renal pelvis. Although it is believed that this may increase the predisposition to stone formation, since urinary stasis will be greater in the kidneys with extrarenal pelvis, surgical procedures can be performed more easily in collector systems with such morphology [2].

Lifetime risk of stone formation is $20 \%$ in adult white males, and $5-10 \%$ in females. Lower calyceal stones constitute $25-35 \%$ of the kidney stones [21]. In the treatment of kidney lower pole stones, shock wave lithotripsy (SWL), percutaneous nephrolithotomy (PNL) and retrograde intrarenal surgery (RIRS) methods are used depending on the size [16]. Factors reducing success for SWL are accepted as the stone's resistance to shock waves (calcium oxalate, monohydrate, cystine stones), narrow infundibulopelvic angle, long lower pole calyx, narrow infundibulum, and long distance from the skin to the stone [17]. In recent years, RIRS has become the treatment option especially for stones smaller than $2 \mathrm{~cm}$ for which SWL has failed [8]. However, there are not many studies assessing the effect of the anatomical structure of the lower pole of the kidney on the success of the RIRS method for kidney lower pole stones. In a study conducted on this subject, preoperative and postoperative first year data were evaluated via the intravenous urography method, and it was concluded that the infundibulopelvic angle, infundibular length and infundibular width of the lower pole of the kidney, especially the infundibular width of the lower pole of the kidney out of three parameters, played a significant role in the clearance of stone fragments [13].

The current study aimed to reveal the anatomy and differences of the renal collecting system in forensic autopsy cases performed in the Department of Forensic Medicine of Cumhuriyet University Faculty of Medicine and also to specify the frequency of negative factors particularly encountered in the surgery of kidney lower pole stones by measuring the kidney lower pole infundibulopelvic anatomy.

\section{MATERIALS AND METHODS}

Our research was conducted in forensic autopsies at Cumhuriyet University Application and Research 
Hospital, Department of Forensic Medicine between September 2017 and September 2018, with the approval of Cumhuriyet University Clinical Research Ethics Committee, dated 11.07.2017 and numbered 2017-07/32. Autopsy cases with previous kidney surgery and trauma history were not included in the study.

The anatomy of the collecting system was photographed and assessed in 82 kidney units obtained from 41 autopsy cases included in the study according to exclusion criteria.

The kidneys and the proximal segment of the ureter of the autopsy cases, whose thorax and abdominal cavity were opened with an incision made from the chin to the pubis, were removed by the autopsy officers. After the kidneys were washed under tap water, an incision was made with a sharp knife in a coronal direction to cover the renal pelvis and ureter, dividing them into two parts. To evaluate the morphology of the pelvicalyceal system and lower infundibulopelvic anatomy, the kidneys lying on a flat surface were photographed in an upright position by placing a measuring ruler next to them.

The photographs were digitally evaluated and grouped according to Bruce et al. [4], Sampaio and Mandarim-De-Lacerda [26] and Ningthoujam et al. [19] classifications in terms of pelvic anatomy (Fig. 1).

Then, the lower calyx infundibulum length and infundibulopelvic angles were measured based on the study by Elbahnasy et al. [6] using the AutoCAD (Version 2016, Autodesk Inc.) programme in digital environment by taking the ruler in the photograph as a reference. The infundibulopelvic angle is the internal angle at the intersection of the ureteropelvic axis and the axis passing through the centre of the lower infundibulum, and the length of the infundibulum was obtained by measuring the distance from the base of the lower calyx group to the lower edge of the renal pelvis. The measurement method is given in Figure 2 . Based on a similar study, the infundibulopelvic angle was categorized as above and below 70 degrees, and the infundibulum length value was categorised in centimetres as above and below $3 \mathrm{~cm}$ (Fig. 2) [13].

\section{Statistical analysis}

The data obtained in our study were uploaded onto the IBM SPSS Statistics for Windows (Version 24.0, IBM Corp.) software. The majority of the data used in the study consists of categorical data. Chi- -square analysis was preferred owing to the presence of categorical variables in the evaluation of the data. Cramer's V coefficient was used as a correction factor in $2 \times 2 \chi^{2}$ analyses. Normal analyses were carried out for other nxm-mesh structures. The confidence level in the tests was considered as $95 \%$.

\section{RESULTS}

The age range of 42 autopsy cases included in the study was 23-75, and the mean age was $49.34 \pm$ \pm 16.81 years. Eleven (26.8\%) of the cases were female, 30 (73.2\%) were male.

When the pelvicalyceal anatomy of the right and left kidneys were compared according to the classification of Ningthoujam [19], bicalyceal and tricalyceal anatomy was found to be more on the left side and multicalyceal anatomy on the right side; however, the difference was statistically insignificant $(p=0.068)$ [19].

Since no morphological features could be defined that would enable it to be included in any group, Sampaio and Mandarim-De-Lacerda [26] evaluation could not be performed in five of our autopsy cases; therefore, the Sampaio classification was evaluated in 77 kidney units. When the right and left kidneys were compared according to this classification, used for the anatomical classification of the renal collecting system, the difference was found to be statistically insignificant ( $p=0.559$ ). However, it was discovered that type $\mathrm{BI}$ defined by Sampaio and Mandarim-De-Lacerda [26] in his study, in which the middle pole of the kidney opened independently to the renal pelvis, consisted of the combination of the upper and lower calyx groups of the renal collecting system on the left side (34.1\%), and that type Al, in which the middle calyx group opened into the upper, lower or both collecting systems, was more on the right side (29.3\%).

When the right and left kidneys were compared according to the Bruce classification [4], which evaluated the pelvis morphology, the difference was found to be insignificant ( $p=0.950$ ). In the current study, the incidence of intrarenal pelvis was found to be $78 \%$, borderline $13.4 \%$, extrarenal pelvis $6.1 \%$ and the rate of absence of pelvis was $2.4 \%$. Findings belonging to these classifications are summarised in Table 1.

When the infundibulum lengths of the right and left kidneys in our study were compared as $<3 \mathrm{~cm}$ and $\geq 3 \mathrm{~cm}$, the difference was found to be insignificant $(p=0.651)$. When the infundibulopelvic angles 


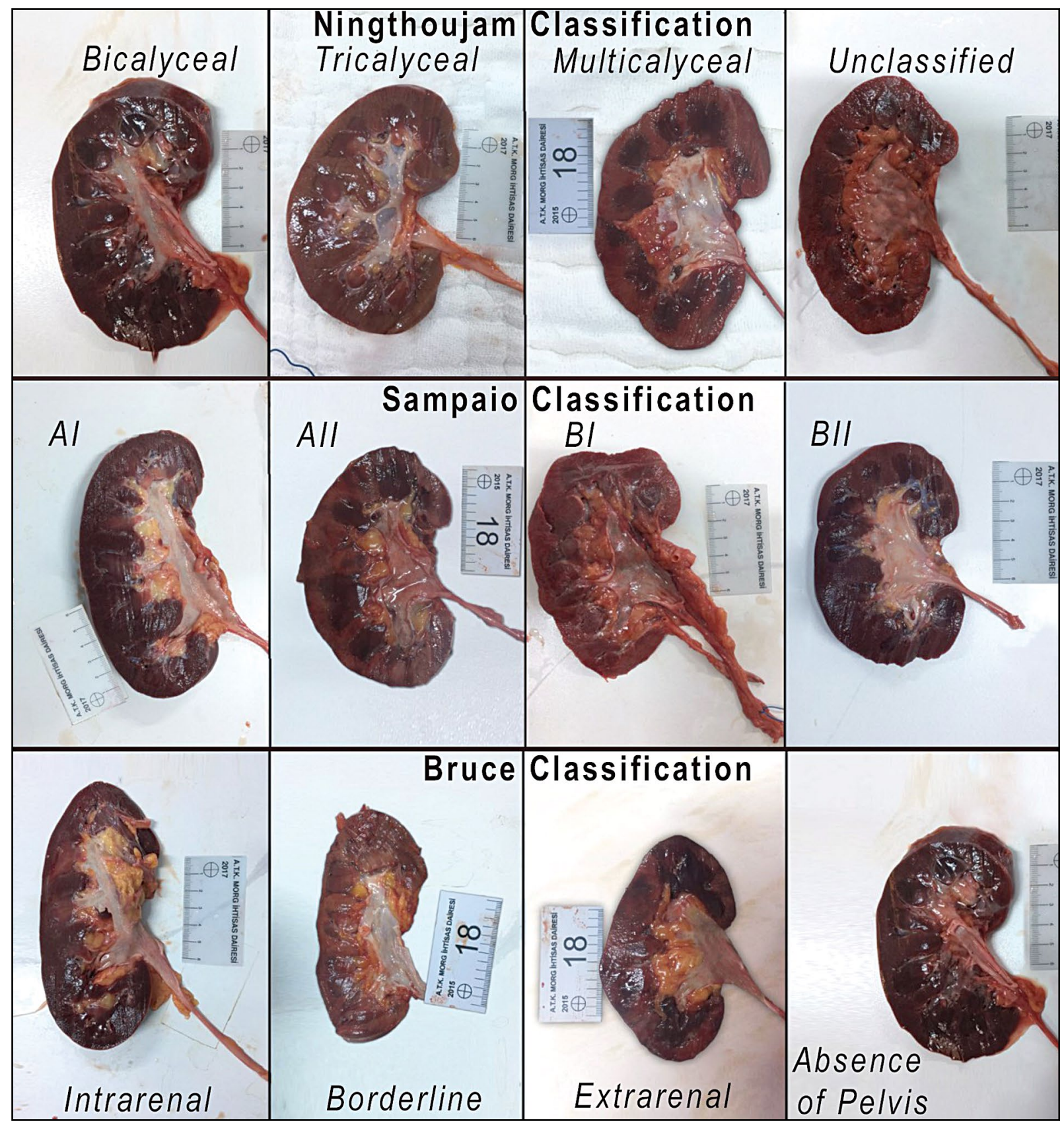

Figure 1. Ningthoujam classification, where the shapes and numbers of calyxes are evaluated, evaluating the openings of major calyces Sampaio classification, Bruce classification, where the main pelvis morphology is evaluated.

of the right and left kidneys were compared as $<70^{\circ}$ and $\geq 70^{\circ}$, the difference was statistically insignificant $(p=0.503)$ (Table 2).

When the renal collecting system was compared in males and females according to the Ningthoujam classification, the difference was found to be insignificant $(p=0.698)$. However, it was seen that the rate of bicalyceal anatomy was higher in males $(35 \%)$ and the rate of tricalyceal anatomy was higher in females (36.4\%). When the anatomical structure of the renal collecting system was compared between genders according to the Sampaio classification, no significant difference was observed $(p=0.932)$ When the pelvic morphologies of males and females were compared according to the Bruce classification, the difference was found to be insignificant ( $p=0.322$ ) (Table 3).

When the infundibular lengths were compared between males and females, it was seen that the infundibular length of less than $3 \mathrm{~cm}$ was more frequent in females, and the infundibular length of $3 \mathrm{~cm}$ and 


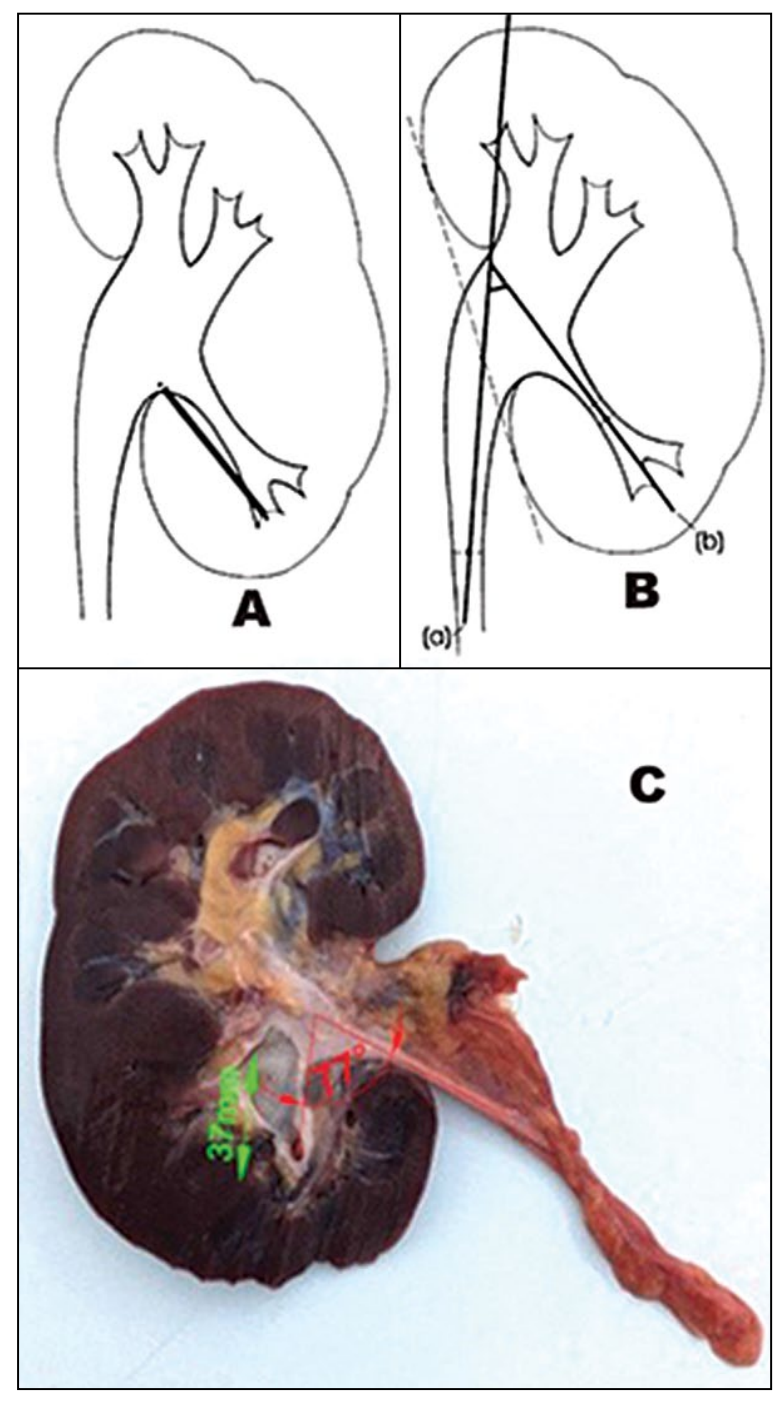

Figure 2. Lower calyx infundibulum length $(\mathbf{A})$ and infundibulopelvic angle (B) measurement, measurement image of a kidney in this study (C).

above was more frequent in males $(p=0.024)$. When the infundibulopelvic angles measured in autopsy cases were compared by gender, although infundibulopelvic angles of $70^{\circ}$ and above (66.7\%) were more frequent in males and below $70^{\circ}$ in females (54.5\%), there was no statistically significant difference in terms of infundibulopelvic angle according to gender $(p=0.081)$ (Table 4).

\section{DISCUSSION}

In our study, in autopsy cases, infundibular length and infundibulopelvic angle, which are among the pelvicalyceal anatomy and negative anatomical factors of the kidney lower pole, were measured and evaluated.
It has been reported that it would be more accurate to evaluate pelvicalyceal morphology in the cadaver, since superposition of the cross-calyx structures over each other in radiological evaluations may lead to incorrect evaluations [1].

In a study by filling polyester into the collecting system in 140 cadavers, the most common calyceal morphology was reported to be type Al and All according to their own classification [26]. Similar results were obtained in an analogous study on cadavers [1]. In contrast, another study on 170 kidney units demonstrated that there were more type BI and BII. Even though the numerical difference is not much significant, it was found that the number of type Al and All was higher in our study, similar to the finding of Sampaio Mandarim-De-Lacerda [26] and Anjana et al. [1] studies (Table 5) [18].

Evaluation of calyx openings according to the Sampaio classification can be important for clinicians. For example, Anjana et al. [1] report that, when endoscopy is attempted with flexible nephroscopy in kidneys with Al type calyceal morphology, the existing anatomy may make it difficult for the device to pass, and also clearing the stone fragments will be easier after SWL in kidneys with type BII morphology where minor calyces open directly to the renal pelvis.

According to the Bruce classification, renal pelvis is divided into four categories as intrarenal, borderline, extrarenal, and absence of renal pelvis. In most studies, same classification is used. In a recent study conducted by Krishnaveni et al. [15] on 44 cadavers, it was reported that the extrarenal pelvis was found at a rate of $31.8 \%$. It has been determined that extrarenal pelvis emerges as a result of the branching of the ureteric bud before reaching the metanephric blastema in the embryological period [22]. When the morphology of the renal pelvis was evaluated in our research, $78 \%$ intrarenal, $13.4 \%$ borderline, $6.1 \%$ extrarenal and $2.4 \%$ absence of renal pelvis were observed. Moreover, there was no statistically significant change in the rate of pelvis morphology seen in the right-left kidney ( $p=0.950)$.

In a study by Anjana et al. [1], the most common position of the renal pelvis was reported to be intrarenal (79\%) according to the Bruce classification, and the extrarenal pelvis and absence of renal pelvis were observed only in the right kidney. In our study, the ratio of right and left difference in renal pelvis morphology is similar to the results of analogical study [9]. Various different figures were reported in studies 
Table 1. Kidney side — Ningthoujam, Sampaio, and Bruce classification comparison

\begin{tabular}{|c|c|c|c|c|c|c|c|}
\hline Ningthoujam classification & Bicalyceal & Tricalyceal & Multicalyceal & Unclassifiable & $\mathbf{p}$ & $\mathbf{p}$ & \\
\hline Left & $15(36.6 \%)$ & $15(36.6 \%)$ & $5(12.2 \%)$ & $6(14.6 \%)$ & 0.031 & 0.068 & \\
\hline Right & $12(29.3 \%)$ & $7(17.1 \%)$ & $12(29.3 \%)$ & $10(24.4 \%)$ & 0.652 & & \\
\hline Total & $27(32.9 \%)$ & $22(26.8 \%)$ & $17(20.7 \%)$ & $16(19.5 \%)$ & 0.289 & & \\
\hline$p$ & 0.564 & 0.088 & 0.09 & 0.317 & & & \\
\hline Sampaio classification & $0^{*}$ & $\mathbf{A l}^{* *}$ & $\mathrm{All}^{* * *}$ & $\mathrm{BI}^{* * * *}$ & $\mathrm{Bll} * * * * *$ & $\mathbf{p}$ & $\mathbf{p}$ \\
\hline Left & $2(4.9 \%)$ & $13(31.7 \%)$ & $7(17.1 \%)$ & $14(34.1 \%)$ & $5(12.2)$ & 0.011 & 0.559 \\
\hline Right & $3(7.3 \%)$ & $12(29.3 \%)$ & $7(17.1 \%)$ & $9(22 \%)$ & $10(24.4)$ & 0.222 & \\
\hline Total & $5(6.1 \%)$ & $25(30.5 \%)$ & $14(17.1 \%)$ & $23(28 \%)$ & $15(18.3)$ & 0.004 & \\
\hline$p$ & 0.655 & 0.841 & 1 & 0.297 & 0.197 & & \\
\hline Bruce classification & Intrarenal & Borderline & Extrarenal & Absent & $\mathbf{p}$ & $\mathbf{p}$ & \\
\hline Left & $33(80.5 \%)$ & $5(12.2 \%)$ & $2(4.9 \%)$ & $1(2.4 \%)$ & $<0.001$ & 0.950 & \\
\hline Right & $31(75.6 \%)$ & $6(14.6 \%)$ & $3(7.3 \%)$ & $1(2.4 \%)$ & $<0.001$ & & \\
\hline Total & $64(78 \%)$ & $11(13.4 \%)$ & $5(6.1 \%)$ & $2(2.4 \%)$ & $<0.001$ & & \\
\hline$p$ & 0.803 & 0.763 & 0.655 & 1 & & & \\
\hline
\end{tabular}

${ }^{*} 0$ : Those that could not be evaluated.

${ }^{* *}$ Al: The collecting system consists of the combination of the upper and lower calyx groups, and the middle calyx group opens to the upper, lower, or both collecting systems.

***All: Similar to type Al, but one or both of the upper and lower calyx groups open to the middle calyx.

${ }^{* * *} \mathrm{BI}$ : The middle pole of the kidney opens to the renal pelvis independently.

*****Bll: The minor calyces of the middle pole of the kidney open to the renal pelvis independently.

Absent — renal pelvis absence

Table 2. Kidney side — infundibulum lengths and infundibulopelvic angle comparison

\begin{tabular}{lcccc}
\hline Infundibulum lengths & $<\mathbf{3} \mathbf{c m}$ & $\geq \mathbf{3} \mathbf{c m}$ & $\mathbf{p}$ & $\mathbf{p}$ \\
\hline Left & $15(36.6 \%)$ & $26(63.4 \%)$ & 0.086 & 0.651 \\
Right & $17(41.5 \%)$ & $24(58.5 \%)$ & 0.274 & \\
Total & $32(39 \%)$ & $50(61 \%)$ & 0.047 & \\
\hline Infundibulopelvic angle & $<\mathbf{7 0 ^ { \circ }}$ & $\geq \mathbf{7 0 ^ { \circ }}$ & $\mathbf{p}$ & $\mathbf{p}$ \\
\hline Left & $19(46.3 \%)$ & $22(53.7 \%)$ & 0.639 & 0.503 \\
Right & $16(39 \%)$ & $25(61 \%)$ & 0.160 & \\
Total & $35(42.7 \%)$ & $47(57.3 \%)$ & 0.185 & \\
\hline
\end{tabular}

regarding the extrarenal pelvis ratio, and they vary between $5 \%$ and $31.8 \%[1,3,9,15]$. In our study, the rate of extrarenal pelvis was found as $6.1 \%$ (Table 6 ).

When collecting systems in 107 kidney units obtained from cadavers were evaluated and it was revealed in a study that $38 \%$ of kidneys had bicalyceal, $26 \%$ had tricalyceal, $33 \%$ had middle pole minor calyces draining into upper and lower major calyces, and in $8 \%$, all minor calyces drained into the renal pelvis without forming a major calyx [7]. Furthermore, the authors also demonstrated that the renal pelvis was generally formed by the combination of two or three major calyces. In another study performed in
2005 by evaluating 100 cadavers ( 80 foetuses and 20 adults) and 100 selected intravenous urography images in India, the researchers observed 20\% bicalyceal, $40 \%$ tricalyceal, $30 \%$ multicalyceal, and $10 \%$ non-evaluable calyceal structure in cadavers, and found $22 \%$ bicalyceal, $51 \%$ tricalyceal, $15 \%$ multicalyceal and $12 \%$ non-evaluable calyceal structures in intravenous urography [19]. In this study, it is seen that tricalyceal structure is more frequent in both cadaver kidneys and intravenous urography evaluations. A study reports the bicalyceal, tricalyceal and multicalyceal rates as $27.3 \%, 20.4 \%$ and $52.3 \%$, respectively [15]. In another study on 100 cadaver kidneys, calyceal morphology was reported as $35 \%$ bicalyceal, $27 \%$ tricalyceal, $23 \%$ multicalyceal, and $15 \%$ non-evaluable [1].

Even though the rate of multicalyceal structure is reported more often in some studies, it is visible that the bicalyceal type is the most common type in this study, as in the study by Anjana et al. (Table 7) [1].

In parallel with the developments in kidney stone treatment in recent years, the prominence of endoscopic surgery such as SWL, PNL, and RIRS requires a better understanding of the pelvicalyceal anatomy. Negative anatomical factors belonging to both pelvicalyceal morphology and the lower kidney pole 
Table 3. Gender — Ningthoujam, Sampaio, and Bruce classification comparison

\begin{tabular}{|c|c|c|c|c|c|c|c|}
\hline Ningthoujam classification & Bicalyceal & Tricalyceal & Multicalyceal & Unclassifiable & $\mathbf{p}$ & $\mathbf{p}$ & \\
\hline Female & $6(27.3 \%)$ & $8(36.4 \%)$ & $4(18.2 \%)$ & $4(18.2 \%)$ & 0.572 & 0.698 & \\
\hline Male & $21(35 \%)$ & $14(23.3 \%)$ & $13(21.7 \%)$ & $12(20 \%)$ & 0.343 & & \\
\hline Total & $27(32.9 \%)$ & $22(26.8 \%)$ & $17(20.7 \%)$ & $16(19.5 \%)$ & 0.289 & & \\
\hline Sampaio classification & $0^{*}$ & $\mathbf{A l}^{* *}$ & All*** & $\mathrm{Bl}^{* * * *}$ & Bll***** & $\mathbf{p}$ & $\mathbf{p}$ \\
\hline Female & $2(9.1 \%)$ & $7(31.8 \%)$ & $4(18.2 \%)$ & $6(27.3 \%)$ & $3(13.6 \%)$ & 0.418 & 0.932 \\
\hline Male & $3(5 \%)$ & $18(30 \%)$ & $10(16.7 \%)$ & $17(28.3 \%)$ & $12(20 \%)$ & 0.016 & \\
\hline Total & $5(6.1 \%)$ & $25(30.5 \%)$ & $14(17.1 \%)$ & $23(28 \%)$ & $15(18.3 \%)$ & 0.004 & \\
\hline Bruce classification & Intrarenal & Borderline & Extrarenal & Absent & $\mathbf{p}$ & $\mathbf{p}$ & \\
\hline Female & $15(68.2 \%)$ & $5(22.7 \%)$ & $2(9.1 \%)$ & $0(0 \%)$ & 0.002 & 0.322 & \\
\hline Male & $49(81.7 \%)$ & $6(10 \%)$ & $3(5 \%)$ & $2(3.3 \%)$ & $<0.001$ & & \\
\hline Total & $64(78 \%)$ & $11(13.4 \%)$ & $5(6.1 \%)$ & $2(2.4 \%)$ & $<0.001$ & & \\
\hline
\end{tabular}

${ }^{*} 0$ : Those that could not be evaluated.

${ }^{* *}$ Al: The collecting system consists of the combination of the upper and lower calyx groups, and the middle calyx group opens to either the upper or lower, or both collecting systems.

***All: Similar to type Al, but one or both of the upper and lower calyx groups open to the middle calyx.

${ }^{* * * *} \mathrm{BI}$ : The middle pole of the kidney opens to the renal pelvis independently.

*****BIl: The minor calyces of the middle pole of the kidney open to the renal pelvis independently.

Absent — renal pelvis absence

Table 4. Gender — infundibulum lengths and infundibulopelvic angle comparison

\begin{tabular}{lcccc}
\hline Infundibulum lengths & $<\mathbf{3} \mathbf{c m}$ & $\geq \mathbf{3} \mathbf{c m}$ & $\mathbf{p}$ & $\mathbf{p}$ \\
\hline Female & $13(59.1 \%)$ & $9(40.9 \%)$ & 0.394 & $0.024^{*}$ \\
Male & $19(31.7 \%)$ & $41(68 \%)$ & 0.005 & \\
Total & $32(39 \%)$ & $50(61 \%)$ & 0.047 & \\
\hline Infundibulopelvic angle & $<70^{\circ}$ & $\geq 70^{\circ}$ & $\mathbf{p}$ & $\mathbf{p}$ \\
\hline Female & $12(54.5 \%)$ & $10(45.5 \%)$ & 0.670 & 0.081 \\
Male & $20(33.3 \%)$ & $40(66.7 \%)$ & 0.035 & \\
Total & $32(39.0 \%)$ & $50(61 \%)$ & 0.094 & \\
\hline
\end{tabular}

*Statistically significant

(infundibulopelvic length, infundibulopelvic angle) affect the clearance of stone fragments after RIRS, PNL and SWL.

Clinically, it is asserted that preoperative evaluation of lower calyceal group anatomy is necessary for optimal treatment of lower calyceal stones with
SWL, PNL and ureteroscopy, and that it is difficult to standardize this evaluation with intravenous urography, and instead, spiral computed tomography is more appropriate today [20].

In a study which evaluated the effect of lower pole calyx anatomy on the clearance of stone fragments after SWL, it was emphasized that the infundibulopelvic angle above $70^{\circ}$ and the infundibulum length less than $50 \mathrm{~mm}$ had a significant effect on the SWL results [11]. In a similar study, it was reported that factors such as infundibulum length and infundibulopelvic angle significantly influenced stone clearance after SWL, wide infundibulopelvic angle or short and wide infundibulum were positive factors affecting stone clearance independently from the infundibulopelvic angle, and that these factors could be important in ureteroscopy [6]. There are other studies on this subject that gave similar results $[24,28]$. Some studies also show that the negative anatomy of the

Table 5. Summary of the studies evaluating the opening of the major calyces and our findings

\begin{tabular}{|c|c|c|c|c|c|c|}
\hline & Number of kidney & $A I^{*}$ & All** & $\left.\mathbf{B}\right|^{* * *}$ & $\mathbf{B} \mathbf{I}^{* * * *}$ & $\mathbf{P}$ \\
\hline Current study & 77 & $32.4 \%$ & $18.2 \%$ & $29.9 \%$ & $19.5 \%$ & 0.186 \\
\hline Sampaio and Mandarim-De-Lacerda [26] & 140 & $45 \%$ & $17 \%$ & $21 \%$ & $16 \%$ & $<0.001$ \\
\hline Bruce et al. [4] & 170 & $33.5 \%$ & $13.5 \%$ & $34.7 \%$ & $18.2 \%$ & $<0.001$ \\
\hline Anjana et al. [1] & 100 & $38 \%$ & $12 \%$ & $29 \%$ & $20 \%$ & 0.002 \\
\hline
\end{tabular}

${ }^{*} \mathrm{Al}$ : The collecting system consists of the combination of the upper and lower calyx groups, and the middle calyx group opens to either the upper or lower or both collecting systems.

${ }^{* *}$ All: Similar to type Al, but one or both of the upper and lower calyx groups open to the middle calyx.

${ }^{* * *} \mathrm{BI}$ : The middle pole of the kidney opens to the renal pelvis independently.

${ }_{* * * *}^{*}$ Bll: The minor calyces of the middle pole of the kidney open to the renal pelvis independently. 
Table 6. The summary of studies evaluating pelvis morphology and our results

\begin{tabular}{lcccccc}
\hline & Number of kidney & Intrarenal & Borderline & Extrarenal & Renal pelvis absence & P \\
\hline Current study & 82 & $78 \%$ & 13.5 & $6.1 \%$ & $2.4 \%$ & $<0.001$ \\
Krishnaveni et al. [15] & 44 & $68.18 \%$ & - & $31.82 \%$ & - & 0.016 \\
Anjana et al. [1] & 100 & $79 \%$ & $13 \%$ & $5 \%$ & $3 \%$ & $<0.001$ \\
Gandhi and Chavan [9] & 196 & $48.5 \%$ & $20.9 \%$ & $21.9 \%$ & $8.7 \%$ & $<0.001$ \\
\hline
\end{tabular}

Table 7. The summary of studies evaluating the shapes and numbers of calyces and our results

\begin{tabular}{lcccccc}
\hline & Number of kidney & Bicalyceal & Tricalyceal & Multicalyceal & Unclassifiable & P \\
\hline Current study & 82 & $32.9 \%$ & $26.8 \%$ & $20.7 \%$ & $19.5 \%$ & 0.289 \\
Anjana et al. [1] & 100 & $35 \%$ & $27 \%$ & $23 \%$ & $15 \%$ & 0.020 \\
Krishnaveni et al. [15] & 44 & $27.3 \%$ & $20.4 \%$ & $52.3 \%$ & - & 0.025 \\
Ningthoujam et al. [19] (cadaver data) & 200 & $20 \%$ & $40 \%$ & $30 \%$ & $10 \%$ & $<0.001$ \\
\hline
\end{tabular}

lower calyx has no effect on stone clearance after SWL $[5,25]$.

A study carried out in our country reported that positive anatomical factors of the kidney lower pole, especially an infundibulopelvic angle above $45^{\circ}$, positively affected the stone clearance after RIRS [23]. In a study, in which the effect of pyelocaliceal anatomy on the success of flexible ureteroscopy was evaluated, when the infundibulopelvic angle was above $90^{\circ}$, the success rate was $87.5 \%$, when between $30-90^{\circ}$, $74.3 \%$, and when below $30^{\circ}$, it was $0 \%$ in lower pole calyx stones. The success rate was $88.2 \%$ when the infundibular length was less than $3 \mathrm{~cm}$, and $61.1 \%$ when longer [10].

A study which investigated the relationship of stone size with infundibulum length, infundibulopelvic angle and infundibular stenosis in patients that underwent RIRS due to lower calyx stones revealed that there was no relationship between stone size and these anatomical features, but infundibulum length and infundibular stenosis make RIRS application difficult [12]. In a study in 2015, it was stressed that infundibulum length, infundibulopelvic angle and stone size did not pose an obstacle to success for RIRS in lower calyx stones, but infundibular width of $\geq 5 \mathrm{~mm}$ significantly affected this success [13]. In a study which compared the anatomy of the collecting system and the stone-free rate in lower pole stones that underwent RIRS, stone size, long infundibulum and infundibulopelvic angle, below $30^{\circ}$ were shown to statistically significantly affect the stone-free rate negatively, whereas the infundibular width did not change it [14].
In a recent similar study conducted in our country, when the infundibulopelvic angle, infundibulum length, infundibular height and stone size were considered, the most important factor affecting the success of RIRS was shown to be the infundibulopelvic angle, and stone size and infundibular height, while not as important as infundibulopelvic angle, were shown to affect RIRS success [27].

\section{CONCLUSIONS AND RECOMMENDATIONS}

The most important result in our study, where the measurements of the collecting system morphologies and lower pole negative anatomical factors were examined in the renal coronal sections of autopsy cases, is that there are more cases with lower pole infundibulum lengths of $\geq 3 \mathrm{~cm}$, and this is more common in males.

The results obtained in our study are substantially similar to the results of similar studies conducted both in our country and in different parts of the world. This reveals that the morphology of the renal collecting system in humans and adverse anatomical factors in the lower pole collecting system are found in roughly similar proportions. Thus, in clinical practice, the evaluation of lower pole negative anatomical factors with computed tomography and, if necessary, with magnetic resonance urography before the treatment may not only contribute to obtaining information about both perioperative complications and the clearance of stone fragments especially after SWL and RIRS but also taking measures accordingly.

Conflict of interest: None declared 


\section{REFERENCES}

1. Anjana TSR, Muthian E, Thiagarajan S, et al. Gross morphological study of the renal pelvicalyceal patterns in human cadaveric kidneys. Indian J Urol. 2017; 33(1): 36-40, doi: 10.4103/0970-1591.194782, indexed in Pubmed: 28197028.

2. Arzoz-Fabregas M, Ibarz-Servio L, Blaco-Casares FJ. Can infindibular heiht predict the clearance of lower pole stone after extracorporeal shochwave litotripsy? J Urol. 2009; 35: 140-150.

3. Brant WE, Helms CA. Fundamentals of diagnostic radiology. 4nd ed. Williams \& Wilkins, Lippincott 2012: 817-830.

4. Bruce SJ, Warmsley R, Ross JA. The abdominal cavity in manual of surgical anatomy. 5th ed. E and S Livingstone Ltd., Edinburgh 1967: 391-403 .

5. Danuser H, Müller R, Descoeudres B, et al. Extracorporeal shock wave lithotripsy of lower calyx calculi: how much is treatment outcome influenced by the anatomy of the collecting system? Eur Urol. 2007; 52(2): 539-546, doi: 10.1016/j.eururo.2007.03.058, indexed in Pubmed: 17400366.

6. Elbahnasy AM, Shalhav AL, Hoenig DM, et al. Lower caliceal stone clearance after shock wave lithotripsy or ureteroscopy: the impact of lower pole radiographic anatomy. J Urol. 1998; 159(3): 676-682, indexed in Pubmed: 9474124.

7. Fine J, Ken EN. The arteries of the human kidney. J Anat. 1966; 100: 881-894.

8. Fuchs AM, Fuchs GJ. Retrograde intra-renal surgery for calculus disease: new minimally invasive treatment approach. J Endourol. 1990; 4: 337-345.

9. Gandhi KR, Chavan S. Revisiting the morphology of pelvicalyceal system in human cadaveric kidneys with a systematic review of literature. Asian J Urol. 2019; 6(3): 249-255, doi: 10.1016/j.ajur.2018.12.006, indexed in Pubmed: 31297316.

10. Geavlete P, Multescu R, Geavlete B. Influence of pyelocaliceal anatomy on the success of flexible ureteroscopic approach. J Endourol. 2008; 22(10): 2235-2239, doi: 10.1089/end.2008.9719, indexed in Pubmed: 18937587.

11. Ghoneim IA, Ziada AM, Elkatib SE. Predictive factors of lower caliceal stone clearance after extracorporeal shock wave lithotripsy (ESWL): A focus on infundibulopelvic anatomy. Eur Urol. 2005; 48: 296-302.

12. Grasso M, Ficazzola M. Retrograde ureteropyeloscopy for lower pole caliceal calculi. J Urol. 1999; 162(6): 1904-1908, doi: 10.1016/s0022-5347(05)68065-2, indexed in Pubmed: 10569534.

13. Hakan K, Yurdaer K, Yakup K, et al. Unfavorable anatomical factors influencing the success of retrograde intra- renal surgery for lower pole renal calculi. Urology J. 2015; 12: 2065-2066.

14. Jessen JP, Honeck P, Knoll T, et al. Flexible ureterorenoscopy for lower pole stones: influence of the collecting system's anatomy. J Endourol. 2014; 28(2): 146-151, doi: 10.1089/ end.2013.0401, indexed in Pubmed: 24083332.
15. Krishnaveni C, Kulkarni R, Kishore Kumar BN. A study of renal calyces by using barium contrast. Int $J$ Anat Res. 2014; 2: 369-374.

16. Lingerman JE, Matlaga BR, Evan AP. Surgical management of upper urinary tract calculi, Wein AJ, Kavoussi LR, Nowick AC, Partin AW, Peters CA (Eds), Campbell-Walsh Urology. 10th ed. Elsevier Saunders, Philadelphia 2012: 1431-1507.

17. Manikandan R, Gall Z, Gunendran T, et al. Do anatomic factors pose a significant risk in the formation of lower pole stones? Urology. 2007; 69(4): 620-624, doi: 10.1016/j. urology.2007.01.005, indexed in Pubmed: 17445636.

18. Marroig B, Favorito LA, Fortes MA. Lower pole anatomy and mid-renal-zone classification applied to flexible ureteroscopy: experimental study using human three-dimensional endocasts. Surg Radiol Anat. 2015; 37: 1243-1249.

19. Ningthoujam DD, Chongtham RD, Sinam SS. Pelvi-calyceal pattern in foetal and adult human kidneys. J Anat Soc India. 2005; 54: 1-11.

20. Pace KT, Weir MJ, Harju M, et al. Individual patient variation and inter-rater reliability of lower calyceal infundibular width on routine intravenous pyelography. BJU Int. 2003; 92(6): 607-609, doi: 10.1046/j.1464-410x.2003.04452.x, indexed in Pubmed: 14511044.

21. Pearle MS, Lotan Y. Urinary lithiasis, etiology, epidemiology, and pathogenesis. In Wein AJ (Ed). Campbell-Walsh Urology. 10th ed. Elsevier Saunders, Philadelphia 2012: 1257-1287.

22. Pollack HM, McClennan BL. Clinical Urography. 2nd ed. Vol. 1. W.B. Saunders Company, Philadelphia 2000: 764-892.

23. Resorlu B, Oguz U, Resorlu EB, et al. The impact of pelvicaliceal anatomy on the success of retrograde intrarenal surgery in patients with lower pole renal stones. Urology. 2012; 79(1): 61-66, doi: 10.1016/j.urology.2011.06.031, indexed in Pubmed: 21855968.

24. Ruggera L, Beltrami P, Ballario R, et al. Impact of anatomical pielocaliceal topography in the treatment of renal lower calyces stones with extracorporeal shock wave lithotripsy. Int J Urol. 2005; 12(6): 525-532, doi: 10.1111/j.14422042.2005.01101.x, indexed in Pubmed: 15985072.

25. Sahinkanat T, Ekerbicer H, Onal B, et al. Evaluation of the effects of relationships between main spatial lower pole calyceal anatomic factors on the success of shock-wave lithotripsy in patients with lower pole kidney stones. Urology. 2008; 71(5): 801-805, doi: 10.1016/j.urology.2007.11.052, indexed in Pubmed: 18279941.

26. Sampaio FJ, Mandarim-De-Lacerda CA. Anatomic classification of the kidney collecting system for endourologic procedures. J Endourol. 1988; 2(3): 247-251, doi: 10.1089/end.1988.2.247.

27. Sari S, Ozok HU, Topaloglu $\mathrm{H}$, et al. The association of a number of anatomical factors with the success of retrograde intrarenal surgery in lower calyceal stones. Urol J. 2017; 14(4): 4008-4014, indexed in Pubmed: 28670667.

28. Sumino $Y$, Mimata $H$, Tasaki $Y$, et al. Predictors of lower pole renal stone clearance after extracorporeal shock wave lithotripsy. J Urol. 2002; 168(4 Pt 1): 1344-1347, doi: 10.1097/01.ju.0000025513.35145.28, indexed in Pubmed: 12352389. 